\title{
CARACTERIZAÇÃo Física E Físico-guímiCa de FRUTOS DE CAJÁ-UMBU (Spondias spp.) ${ }^{1}$
}

\author{
José Severino de LIRA JÚNIOR ${ }^{2, *}$, Rosimar dos Santos MUSSER ${ }^{2}$, Enayde de Almeida MELO², \\ Maria Inês Sucupira MACIEL ${ }^{2}$, Ildo Eliezer LEDERMAN ${ }^{3}$, Venézio Felipe dos SANTOS ${ }^{3}$
}

\begin{abstract}
RESUMO
Este trabalho teve como objetivo efetuar a caracterização física e físico-química de frutos de genótipos de cajá-umbu (Spondias spp.) cultivados sob as condições climáticas da Zona da Mata de Pernambuco, visando identificar materiais promissores para uso comercial e para trabalhos de melhoramento genético. Frutos de cajá-umbu provenientes da coleção de germoplasma instalada na Estação Experimental de Itambé-PE foram submetidos às determinações de peso de fruto (PF), peso da semente (PS), rendimento de polpa (RP), relação entre os diâmetros longitudinal e transversal do fruto (relação DL/DT), pH, sólidos solúveis totais (SST), acidez total titulável (ATT) e relação SST/ATT. Constatou-se que o PF e o PS apresentaram variação significativa sem, contudo, haver diferença no RP e na relação DL/DT dos frutos. A análise dos dados revelou haver diferença estatisticamente significativa entre os valores de pH, SST, ATT e SST/ATT dos frutos dos genótipos. Todos os genótipos reúnem características físicas exigidas pelas indústrias de processamento. No que se refere à relação SST/ATT, os genótipos 6;10;19; 21; 23 e 27 apresentaram os melhores resultados.

Palavras-chave: cajá-umbu, Spondias spp., germoplasma.
\end{abstract}

\section{SUMMARY}

PHYSICAL AND PHYSICO-CHEMICAL CARACTERIZATION OF “CAJÁ-UMBU” FRUITS. This work had as objective the physical and physico-chemical characterization of fruits of cajá-umbu (Spondias spp.) genotypes cultivated under climatic conditions of the Zone of Forest of Pernambuco, aiming at identifying promising materials for commercial use and for works of genetic improvement. Fruits of cajá-umbu from a collection of germ-plasm installed at Experimental Station of Itambé-PE were submitted to the following determinations: fruit and seed weight (FW and SW), pulp yield (PY), relation between longitudinal and transversal diameter (LD/TD), $\mathrm{pH}$, total soluble solids (TSS), total titrable acidity (TTA) and the relation TSS/TTA. It was evidenced that the weight of the fruits and the seeds had presented significant variation without, however, presenting difference in the RP and relation LD/TD of the fruits. The $\mathrm{pH}$, TSS, TTA and TSS/TTA for the fruits from the genotypes showed significant differences.

Keywords: cajá-umbu, Spondias spp., germ-plasm.

\section{1 - INTRODUÇÃO}

Pertencente à família Anacardiaceae, o cajá-umbu (Spondias spp.) é uma frutífera nativa do Nordeste brasileiro ainda em fase de domesticação, originada por possíveis cruzamentos naturais entre o cajá (Spondias mombim L.) e o umbu (Spondias tuberosa Arr. Cam.) que apresenta acentuada variabilidade em função das variações morfológicas entre folhas e frutos $[13,14,8]$.

O extrativismo é a forma de exploração desta espécie que apresenta grande potencial agroindustrial e é encontrada espontaneamente nas regiões semi-áridas, sub-úmida e semiúmida do Nordeste brasileiro. Seus frutos, por apresentarem boa aparência, elevado teor de vitamina C e de glicídios, além de aroma agradável e sabor agridoce, são bastante apreciados, tanto para o consumo in natura, como também, na forma de sucos, doces, picolés e sorvetes [6, 8].

O fruto de cajá-umbu é caracterizado como uma drupa arredondada, de cor amarela, casca fina e lisa, com endo-

\footnotetext{
${ }^{1}$ Recebido para publicação em 11/01/2005. Aceito para publicação em 11/10/2005 (001460). Parte da dissertação do primeiro autor apresentada ao Programa de Pós-Graduação em Agronomia/Melhoramento Genético de Plantas da Universidade Federal Rural de Pernambuco- UFRPE.

${ }^{2}$ Universidade Federal Rural de Pernambuco - UFRPE, Rua Dom Manoel de Medeiros s/n, Dois Irmãos, Recife, PE, CEP: 52171-900, (81) $3302-$ 1253,lira.jr@bol.com.br,rmusser@ufrpe.br,enayde@hotmail.com, mismaciel@ufrpe.br.

${ }^{3}$ Pesquisadores da Empresa Pernambucana de Pesquisa Agropecuária - IPA, Av. Gal. San Martin, 1371, Bonji, Caixa Postal 1022, CEP: 50761-000, Recife,PE, (81) 3445-2200, ildo@ipa.br,venezio@ipa.br.

*A quem a corespondência deve ser enviada.
}

carpo, chamado de "caroço", grande, branco, suberoso e enrugado localizado na parte central do fruto, no interior do qual se encontram os lóculos, que podem ou não conter uma semente [14, 8].

Diversos fatores influenciam as características físicas e físico-químicas de frutos, dentre os quais destacam-se a constituição genética, condições edafoclimáticas, tratos culturais e tratamento pós-colheita [9, 14].

Os caracteres físicos dos frutos referentes à aparência externa, tamanho, forma e cor da casca, e as características físico-químicas relacionadas ao sabor, odor, textura e valor nutritivo, constituem atributos de qualidade à comercialização e utilização da polpa na elaboração de produtos industrializados $[4,11]$.

O aproveitamento socioeconômico e a demanda de pesquisas de espécies frutíferas nativas, como o cajáumbu, têm sido inibidos tanto pela forte pressão do mercado consumidor de frutas tradicionais de clima tropical e subtropical, já adaptadas, como também pelo mercado de frutas de clima temperado, aclimatadas. Porém, a oferta de novas alternativas de frutas frescas para o consumo in natura e matéria-prima para agroindústrias constituem uma preciosa fonte de alimentos e riqueza para o país $[6,10,17]$.

Neste contexto, a caracterização de genótipos presentes em coleções de germoplasma torna-se necessária para que estes recursos genéticos sejam utilizados em programas de melhoramento. Além disso, a caracterização permite 
identificar genótipos potencialmente úteis com produção de frutos tanto para consumo in natura, quanto para processamento da polpa [17].

Alguns trabalhos [14, 16, 8, 15] têm sido realizados com o intuito de caracterizar física e físico-quimicamente frutos de cajá-umbu provenientes de vários locais do Nordeste brasileiro, estimulando o cultivo comercial em bases tecnológicas modernas e incentivando as indústrias de beneficiamento. Assim, este trabalho teve como objetivo caracterizar física e físico-quimicamente frutos de genótipos de cajá-umbu cultivados sob as condições climáticas da Zona da Mata de Pernambuco, visando identificar materiais promissores para uso comercial e para trabalhos de melhoramento genético.

\section{2 - MATERIAL E MÉtOdOS}

Foi estudada a coleção de germoplasma de cajá-umbu que se encontra instalada na Estação Experimental de Itambé, pertencente à Empresa Pernambucana de Pesquisa Agropecuária - IPA ( $7^{\circ} 24^{\prime} 50^{\prime \prime}$ de latitude sul e $35^{\circ} 06^{\prime} 30^{\prime \prime}$ de longitude oeste), localizada na mesorregião da Mata Pernambucana, microrregião da Mata Setentrional, altitude de $190 \mathrm{~m}$ acima do nível do mar, solo classificado como Podzólico vermelho-amarelo e vegetação original do tipo Floresta Subperenefólia. O clima, do tipo AS' na classificação de Köppen, é quente e úmido, com índice pluviométrico médio de $1200 \mathrm{~mm} / \mathrm{ano}$, temperatura média anual de $24^{\circ} \mathrm{C}$ e umidade relativa média do ar de $80 \%$, com os meses mais chuvosos ocorrendo geralmente de abril a julho [7].

A coleção de germoplasma foi implantada em 1991, através de propagação sexuada, com 33 genótipos, sendo cada um representado por uma planta, em espaçamento $12 \times 12$ m. A coleção foi formada através de prospecções e de visitas às áreas de ocorrência espontânea do cajá-umbu, na microrregião do Sertão do Araripe, que abrange, além de Pernambuco, os Estados do Ceará e Piauí. Das plantas desta região, foram coletados frutos maduros para proceder sua caracterização e extração da semente e, posteriormente, formação das mudas para compor a coleção.

Durante a fenofase de frutificação, frutos maduros de dezenove genótipos de cajá-umbu foram coletados, aleatoriamente. De cada genótipo, foram retirados oito frutos por quadrante, seguindo o sentido dos pontos cardeais, no estádio quatro de maturação de frutos totalmente amarelos (4 FTA), de acordo com a classificação descrita por LIMA et al. [8], totalizando 32 frutos por planta. Após a coleta, devidamente identificados, os frutos foram acondicionados em caixa de isopor e imediatamente transportados para o Laboratório de Análises Físico-químicas e Sensorial de Alimentos do Departamento de Ciências Domésticas da Universidade Federal Rural de Pernambuco - UFRPE, onde foram submetidos às determinações analíticas.

Para a caracterização física dos frutos foram considerados: peso do fruto ( $\mathrm{PF}$ ), em gramas, obtidos através de pesagem individual do fruto em balança semi-analítica; peso da semente (PS), em gramas, utilizando balança semi-analítica, após secagem em estufa a $70^{\circ} \mathrm{C}$ até atingirem peso constante; rendimento de polpa (RP), em porcentagem, obtido pela divisão entre o peso da polpa e o peso do fruto multiplicado por 100 e a relação entre os diâmetros longitudinal e transversal (DL/DT), medidos com paquímetro [1].

Para as análises físico-químicas, os frutos de cada quadrante foram macerados em peneira para obtenção da polpa, a qual foi submetida às determinações do potencial hidrogeniônico (pH); sólidos solúveis totais (SST) expressos emºBrix, utilizando refratômetro ATAGO N3; acidez total titulável (ATT), expressa em porcentagem de ácido cítrico e a relação SST/ATT [1].

Adotou-se o delineamento experimental inteiramente casualizado, sendo os dados submetidos à análise de variância utilizando-se o programa computacional SWNTIA (EMBRAPA, 1996), versão 4.2.1, e as médias comparadas pelo teste de Tukey a $5 \%$ de probabilidade [5].

\section{3 - RESULTADOS E DISCUSSÃO}

As características físicas dos frutos dos genótipos de cajá-umbu encontram-se apresentadas na Tabela 1. Foi constatado que o PF e PS apresentaram variação significativa sem, contudo, haver diferença no RP e na relação DL/DT dos frutos.

Em função da ausência de legislação específica que defina valores para tamanho de frutos de cajá-umbu destinados às indústrias processadoras, utilizou-se como parâmetro de comparação a classificação para cajá estabelecida por BOSCO, AGUIAR FILHO \& BARROS [2], por tratar-se de frutos do mesmo gênero com características semelhantes. Segundo estes autores, são considerados: grandes, os frutos que possuem peso superior a 15 g; médios aqueles com peso entre 12 e $15 \mathrm{~g}$; e pequenos os frutos com peso inferior a 12 g. Assim, os frutos dos genótipos estudados podem ser considerados grandes por terem apresentado peso médio de 17,99 a 24,80 g. Vale ressaltar que dos genótipos da coleção, 10 possuíam frutos com peso médio superior a 20,69 g, com destaque para os genótipos 12, 8, 10 e 27, que apresentaram os maiores valores médios de PF (24,80; 23,55; 23,41 e 23,29 g, respectivamente).

Variação semelhante de PF foi encontrada por SILVA JÚNIOR et al. [15], estudando 36 genótipos de cajá-umbu da mesma coleção (19,3 a 26,8 g) e por LIMA et al. [8], em frutos de umbu-cajazeira, em cinco estádios de maturação, oriundos do Brejo Paraibano, município de Areia-PB (17,77 g a $22,30 \mathrm{~g})$.

Sabe-se que o peso médio de frutos é uma característica importante para o mercado de frutas frescas, uma vez que os frutos mais pesados são também os de maiores tamanhos, tornando-se mais atrativos para os consumidores.

Entretanto, para frutos destinados à elaboração de produtos como sucos, doces, picolés e sorvetes, os parâmetros físico-químicos relacionados à acidez total titulável e ao teor de sólidos solúveis totais são mais relevantes [4, 11]. 
TABELA 1 - Características físicas de frutos de 19 genótipos de cajá-umbu cultivados sob condições climáticas da Zona da Mata de Pernambuco

\begin{tabular}{|c|c|c|c|c|}
\hline Genótipo & PF (g) & PS (g) & RP (\%) & DL/DT \\
\hline 3 & $18,86( \pm 0,74) \mathrm{de}^{*}$ & $3,15( \pm 0,06)$ bcde & $82,70( \pm 0,65) a$ & $1,17( \pm 0,01) a$ \\
\hline 4 & $19,43( \pm 0,45)$ cde & $3,06( \pm 0,16)$ bcde & $83,76( \pm 1,08) a$ & $1,16( \pm 0,01) a$ \\
\hline 6 & $22,49( \pm 0,53)$ abcd & $3,16( \pm 0,11)$ bcde & $85,63( \pm 0,79) a$ & $1,14( \pm 0,01) a$ \\
\hline 8 & $23,55( \pm 1,02) a b$ & $4,18( \pm 0,08)$ a & $81,94( \pm 0,58) a$ & $1,14( \pm 0,01) a$ \\
\hline 10 & $23,41( \pm 1,02) a b$ & $3,38( \pm 0,18) \mathrm{bcd}$ & $85,23( \pm 1,14) a$ & $1,15( \pm 0,01) a$ \\
\hline 13 & $19,18( \pm 0,88) \mathrm{de}$ & $3,22( \pm 0,07)$ bcde & $82,58( \pm 0,78) a$ & $1,14( \pm 0,01) a$ \\
\hline 14 & $20,92( \pm 0,68)$ abcde & $3,19( \pm 0,04)$ bcde & $84,45( \pm 0,36) a$ & $1,19( \pm 0,01) a$ \\
\hline 15 & $18,97( \pm 0,76) \mathrm{de}$ & $3,20( \pm 0,11)$ bcde & $82,59( \pm 1,12) a$ & $1,15( \pm 0,02)$ a \\
\hline 17 & $22,59( \pm 0,63)$ abcd & $3,54( \pm 0,02) b c$ & $84,06( \pm 0,51) a$ & $1,17( \pm 0,02) a$ \\
\hline 19 & $21,07( \pm 1,11)$ abcde & $3,32( \pm 0,10) \mathrm{bcd}$ & $83,90( \pm 0,47) a$ & $1,19( \pm 0,02) a$ \\
\hline 23 & $18,22( \pm 0,25) \mathrm{e}$ & $2,69( \pm 0,01) \mathrm{e}$ & $84,87( \pm 0,09) a$ & $1,16( \pm 0,01) \mathrm{a}$ \\
\hline 26 & $18,86( \pm 0,58)$ de & $2,97( \pm 0,09) \mathrm{cde}$ & $83,88( \pm 0,23) a$ & $1,21( \pm 0,01) a$ \\
\hline 27 & $23,29( \pm 0,87) a b c$ & $3,31( \pm 0,03) \mathrm{cde}$ & $85,45( \pm 0,61) a$ & $1,15( \pm 0,01) a$ \\
\hline 28 & $18,13( \pm 0,44) \mathrm{e}$ & $2,88( \pm 0,11) \mathrm{de}$ & $83,94( \pm 0,85)$ a & $1,17( \pm 0,01) a$ \\
\hline Média & 20,69 & 3,24 & 83,79 & 1,17 \\
\hline DMS & 3,91 & 0,59 & 4,19 & 0,15 \\
\hline CV \% & 7,31 & 7,01 & 1,93 & 4,98 \\
\hline
\end{tabular}

*Médias seguidas de mesma letra não diferem estatisticamente entre si, ao nível de $5 \%$ de probabilidade, pelo Teste de Tukey; ( $(+)=$ desvio padrão; DMS=diferença média significativa; $\mathrm{CV} \%=$ coeficiente de variação; $\mathrm{PF}=$ peso do fruto; $\mathrm{PS}=$ peso da semente; $\mathrm{RP}=$ rendimento em polpa; $\mathrm{DL} / \mathrm{DT}=$ relação entre o diâmetro longitudinal e transversal do fruto

Quanto ao PS, os frutos apresentaram um valor médio de 3,24 g, cujo peso variou de 2,69 g (genótipo 5) a 4,18 g (genótipo 8), correspondendo em termos médios a 13,00 e $20,20 \%$ da massa do fruto, respectivamente. Constatou-se que os genótipos, cujos frutos foram mais pesados, também, apresentaram maior peso de sementes, sugerindo haver relação direta entre estas variáveis.

Estes resultados demonstraram que as sementes representaram menor proporção dos frutos quando comparadas aos dados de SILVA JÚNIOR et al. [15], que detectaram valores médios de 21,90 a 35,70\% de semente em relação aos frutos de cajá-umbu coletados em genótipos na região do Araripe, Pernambuco, Brasil.

Um dos atributos de qualidade para a comercialização de frutos é o menor peso de sementes por fruto. Esta variável influencia diretamente o percentual de rendimento, também considerado um atributo de qualidade, especialmente para os frutos destinados à elaboração de produtos, cujo valor mínimo exigido pelas indústrias processadoras é de $40 \%[4,11]$.

Os frutos dos genótipos apresentaram um bom percentual de rendimento em polpa (83,79\%), atingindo os frutos do genótipo 6 , o maior valor $(85,63 \%)$ e os do genótipo 8 , o menor $(81,94 \%)$. Estes resultados demonstraram haver relação negativa entre o peso da semente e o rendimento em polpa.
SILVA JÚNIOR et al. [15] obtiveram um menor rendimento médio de polpa para frutos de cajá-umbu com variação de 54,5 a 66,5\%.

A relação DL/DT variou de 1,14 (genótipo 8) a 1,29 (genótipo 12), com valor médio de 1,17. Esta variável é indicadora do formato do fruto, que é mais arredondado à medida que este quociente aproxima-se de 1 . As indústrias dão maior preferência aos frutos arredondados, por facilitarem as operações de limpeza e processamento [4, 11, 12].

Os frutos do genótipo 12, cujo diâmetro médio longitudinal foi $29 \%$ superior ao diâmetro médio transversal, apresentam formato mais ovalado do que os demais, embora a relação DL/DT de todos os genótipos não tenha apresentado diferença significativa. $O$ valor referente à relação média DL/DT de umbu-cajazeira, apresentado por LIMA et al. [8], foi de 1,32, variando de um mínimo de 1,10 a um máximo de 1,46 .

As características físico-químicas dos frutos dos genótipos de cajá-umbu estão apresentadas na Tabela 2. A análise dos dados revela haver diferença estatisticamente significativa entre os genótipos quanto aos valores de $\mathrm{pH}$, SST, ATT e SST/ATT dos frutos.

Considerando não haver legislação específica referente ao Padrão de Identidade e Qualidade (PIQ) para polpa de cajá-umbu, os dados referentes a estas variáveis foram con- 
Caracterização física e físico-química de frutos de cajá-umbu (Spondias spp.), Lira Júnior et al.

TABELA 2 - Características físico-químicas de frutos de 19 genótipos de cajá-umbu cultivados sob condições climáticas da Zona da Mata de Pernambuco

\begin{tabular}{|c|c|c|c|c|}
\hline Genótipo & $\mathrm{pH}$ & SST ( ${ }^{\circ}$ Brix) & ATT (\% ác. cítrico) & SST/ATT \\
\hline 3 & $2,17( \pm 0,04)$ efg & $16,07( \pm 0,48) a$ & $1,94( \pm 0,09) a b$ & $8,30( \pm 0,45)$ def \\
\hline 4 & $1,75( \pm 0,02) \mathrm{k}$ & $15,75( \pm 0,29) a b$ & $1,73( \pm 0,02)$ abcde & $9,08( \pm 0,23)$ abcdef \\
\hline 5 & $2,20( \pm 0,04)$ efg & $15,17( \pm 0,43) a b c$ & $1,86( \pm 0,10) a b c$ & $8,16( \pm 0,28)$ ef \\
\hline 6 & $2,47( \pm 0,02) a b c$ & $13,60( \pm 0,21)$ cde & $1,30( \pm 0,06) \mathrm{fg}$ & $10,48( \pm 0,42) a b$ \\
\hline 8 & $2,47( \pm 0,02)$ abc & $14,85( \pm 0,09)$ abcd & $1,76( \pm 0,02)$ abcd & $8,44( \pm 0,16)$ cdef \\
\hline 10 & $2,57( \pm 0,02) a$ & $14,80( \pm 0,27)$ abcde & $1,36( \pm 0,05)$ efg & $10,94( \pm 0,56) a$ \\
\hline 12 & $2,27( \pm 0,04)$ def & $13,25( \pm 0,47) \mathrm{de}$ & $1,54( \pm 0,03)$ cdefg & $8,60( \pm 0,47)$ bcdef \\
\hline 13 & $1,87( \pm 0,02) i j k$ & $15,50( \pm 0,45) a b$ & $2,02( \pm 0,06) a$ & $7,65( \pm 0,07) f$ \\
\hline 14 & $1,95( \pm 0,02)$ hij & $15,12( \pm 0,31)$ abcd & $1,76( \pm 0,10)$ abcd & $8,67( \pm 0,50)$ bcdef \\
\hline 15 & $2,07( \pm 0,04) \mathrm{gh}$ & $14,15( \pm 0,46)$ bcde & $1,86( \pm 0,09) a b c$ & $7,60( \pm 0,22) f$ \\
\hline 17 & $2,05( \pm 0,02) \mathrm{ghi}$ & $15,55( \pm 0,58) a b$ & 1,60 ( $\pm 0,06)$ bcdefg & $9,72( \pm 0,13)$ abcde \\
\hline 19 & $2,15( \pm 0,02) \mathrm{fg}$ & $15,30( \pm 0,30) a b c$ & $1,52( \pm 0,09)$ cdefg & $10,18( \pm 0,67)$ abcd \\
\hline 20 & $2,30( \pm 0,04) \mathrm{cdef}$ & $15,40( \pm 0,25) a b c$ & $1,76( \pm 0,13)$ abcd & $8,87( \pm 0,56)$ bcdef \\
\hline 21 & $2,45( \pm 0,02)$ abcd & $15,05( \pm 0,20)$ abcd & $1,46( \pm 0,02)$ defg & $10,29( \pm 0,31) a b c$ \\
\hline 22 & $2,45( \pm 0,02)$ abcd & $14,67( \pm 0,07)$ abcde & $1,65( \pm 0,03)$ abcdef & $8,87( \pm 0,18)$ bcdef \\
\hline 23 & $1,85( \pm 0,02) j k$ & $16,00( \pm 0,08) a b$ & $1,57( \pm 0,02)$ bcdefg & $10,18( \pm 0,14)$ abcd \\
\hline 26 & $1,87( \pm 0,04) i j k$ & $13,52( \pm 0,53)$ cde & $1,89( \pm 0,06) a b c$ & $7,14( \pm 0,22) \mathrm{f}$ \\
\hline 27 & $2,50( \pm 0,04) a b$ & $12,95( \pm 0,05) \mathrm{e}$ & $1,25( \pm 0,02) \mathrm{g}$ & $10,48( \pm 0,42) a b$ \\
\hline 28 & $2,35( \pm 0,05)$ bcde & $15,35( \pm 0,46) a b c$ & $1,81( \pm 0,10)$ abcd & $8,60( \pm 0,47)$ bcdef \\
\hline Média & 2,20 & 14,84 & 1,66 & 9,05 \\
\hline DMS & 0,18 & 1,86 & 0,37 & 1,92 \\
\hline CV \% & 3,29 & 4,84 & 8,67 & 8,21 \\
\hline
\end{tabular}

*Médias seguidas de mesma letra não diferem estatisticamente entre si, ao nível de $5 \%$ de probabilidade, pelo Teste de Tukey; $( \pm$ )=desvio padrão DMS=diferença média significativa; $\mathrm{CV} \%=$ coeficiente de variação; $\mathrm{pH}=$ potencial hidrogeniônico; SST=sólidos solúveis totais; ATT=acidez total titulável; SST/ATT relação.

frontados com os valores para cajá, fruto do mesmo gênero com características bastante semelhantes, estabelecidos pelo Ministério da Agricultura Pecuária e Abastecimento, através da Instrução Normativa ${ }^{\circ} 122$, de 13 de setembro de 1999, a saber: $\mathrm{pH}<2,20$; $\mathrm{SST}>9,00^{\circ} \mathrm{Brix}$; $\mathrm{ATT}>0,90 \%$ de ácido cítrico e relação SST/ATT $>10,00$ [3].

Os frutos dos genótipos apresentaram o potencial hidrogeniônico (pH) que variou de 1,75 (genótipo 4) a 2,57 (genótipo 10), com valor médio de 2,20. Estes valores foram semelhantes aos encontrados por SANTOS [14], LIMA et al.[8] e SILVA JÚNIOR et al. [15], cujas variações de pH para cajá-umbu foram respectivamente de: 2,0 a 2,2; 2,1 1 a 2,17 e 2,5 a 3,0 .

Dentre os genótipos estudados, destacaram-se o 3, 4, $13,14,15,17,19,23$ e 26 por apresentarem $\mathrm{pH}<2,20$, estabelecido como atributo de qualidade pela legislação, por favorecer a conservação da polpa, evitando o crescimento de leveduras [3, 8].

Para sólidos solúveis totais (SST), todos os genótipos apresentaram valores acima do estabelecido pela legislação [3], com variação de 12,95 (genótipo 27) a $16,07^{\circ} \mathrm{Brix}$ (genótipo 3 ). Os valores de SST foram semelhantes aos encontrados por SANTOS [14], que relatou variação de 13,80 a $14,47^{\circ} \mathrm{Brix}$, e superiores aos relatados por LIMA et al. [8] e SILVA JÚNIOR et al.
[15], com variações de 11,00 a $11,25^{\circ}$ Brix e de 9,90 a $15,5^{\circ}$ Brix, respectivamente.

Considerando-se essa variável, todos os frutos de todos os genótipos são propícios para a produção de sucos pois, segundo LIMA et al. [8], frutos destinados para este fim tecnológico devem possuir valores de SST superiores a $8 \%$.

Com relação à acidez total titulável (ATT), a média foi de 1,66\% em ácido cítrico, com variação de 1,25 (genótipo 27) a 2,02\% em ácido cítrico (genótipo 13). LIMA et al. [8] obtiveram um valor médio de 1,91\%, com variação de 1,55 a 2,40\%, enquanto SILVA JÚNIOR et al. [15] apresentaram ATT média de 1,20\%, com variação de 0,74 a 1,49\%. De acordo com LIMA et al. [8] e PINTO et al. [12], podem-se considerar os genótipos com ATT acima de 1,00\% em ácido cítrico como os de maior interesse para a agroindústria, tendo em vista não haver necessidade da adição de ácido cítrico para conservação da polpa, artifício utilizado para tornar o meio impróprio ao desenvolvimento de microrganismos. Todos os genótipos apresentaram porcentagens de ácido cítrico acima do valor mínimo estabelecido para cajá [3].

A relação SST/ATT propicia uma boa avaliação do sabor dos frutos, sendo mais representativa do que a medição isolada de açúcares e de acidez [12]. Os genótipos apresentaram SST/ATT que variou de 7,14 (genótipo 26) 
a 10,94 (genótipo 10). Dos 19 genótipos de cajá-umbu analisados, seis apresentaram relações de SST/ATT acima do valor mínimo $(10,00)$ estabelecido pelo PIQ [3]. Estes valores foram maiores do que os apresentados por LIMA et al. [8] que praticamente não verificaram variação entre os valores médios (6,28 a 6,29); em contrapartida, SILVA JÚNIOR et al. [15] apresentaram valores maiores, sendo a média de 11,13 , com variação de 4,56 a 15,30.

\section{4 - CONCLUSÕES}

As determinações físicas demonstraram que os genótipos de cajá-umbu possuem variações referentes às variáveis de peso de frutos e peso de sementes. Todos os genótipos de cajá-umbu reúnem as características físicas exigidas pelas indústrias de processamento. Os genótipos 6, 8, 10, 12, 14, $17,19,21,22$ e 27 destacam-se por apresentarem pesos de frutos e rendimento de polpa superiores aos requisitados pela comercialização in natura e pelas agroindústrias.

As determinações físico-químicas demonstraram haver variação entre os genótipos de cajá-umbu na Zona da Mata de Pernambuco, referente ao potencial hidrogeniônico $(\mathrm{pH})$, acidez total titulável (ATT), sólidos solúveis totais (SST) e relação (SST/ATT).

Considerando a relação SST/ATT, os frutos de cajá-umbu que apresentam as melhores características físico-químicas para agroindústria são os provenientes dos genótipos 6,10 , $19,21,23$ e 27.

\section{5 - REFERÊNCIAS BIBLIOGRÁFICAS}

[1] ASSOCIATION OF OFFICIAL AGRICULTURAL CHEMISTS, Official Methods of Analysis of the Association of Agricultural Chemists, $11^{\text {th }}$ ed., Washington, 1990.

[2] BOSCO, J.; AGUIAR FILHO, S.P.D.; BARROS, R.V. Banco ativo de germoplasma de cajá no Estado da Paraíba. In: Workshop para curadores de banco de germoplasma de espécies frutíferas. Brasília: Embrapa-Cenargen. p. 80-85. 1999.

[3] BRASIL. Ministério da Agricultura e do Abastecimento. Instrução Normativa ${ }^{\circ} 122$, de 10 de setembro de 1999. Diário Oficial da República Federativa do Brasil, Brasília, 13 de set. de 1999. Seção 1, p. 72-76.

[4] CHITARRA, M.I.F.; CHITARRA, A.B. Pós-colheita de Frutos e Hortaliças: Fisiologia e Manuseio. Lavras: ESAL/Faepe, 320 p.1990.

[5] EMBRAPA. Centro Nacional de Pesquisa Tecnológica em Informática para Agricultura. SWNTIA, versão 4.2.1, instalação e programa. Campinas, 1996.

[6] GIACOMETTI, D.C. Recursos genéticos de frutíferas nativas do Brasil. In: Simpósio nacional de recursos genéticos de frutíferas nativas, 1, 1992, Cruz das Almas: Embrapa Mandioca e Fruticultura, 1993. p. 13-27.

[7] JACOMINE, P.K.T.; CAVALCANTI, A.C.; BURGOS, N.; PESSOA, S.C.P.; SILVEIRA, C.O., Levantamento Exploratório - Reconhecimento de Solos do Estado de Pernambuco. MA-DNPEA/SUDENE-DRN, Recife:
Boletim Técnico, 26/SUDENE-DRN. Série Pedológica, 14, 359 p., 1973.

[8] LIMA, E.D.P.A.; LIMA, C.A.A; ALDRIGUE, M.L.; GONDIM, P.S. Caracterização física e química dos frutos da umbu-cajazeira (Spondias spp.) em cinco estádios de maturação, da polpa e néctar. Revista Brasileira de Fruticultura. Jaboticabal, v. 24, n. 2, p. 338-343, 2002.

[9] LOPES, W.F. Propagação Assexuada de Cajá (Spondias mombim L.) e Cajá-umbu (Spondias spp) através de Estacas. Areia: UFPB/CCA, 1997. 40 p. Trabalho de conclusão de curso (Graduação em Agronomia). Universidade Federal da Paraíba (UFPB).

[10] MORAES, V.H.F.; MULLER, C.H.; SOUZA, A.G.C.; ANTÔNIO I.C. Native fruit species of economic potential from the Brazilian Amazon. Ang. Bot. v. 68, p. 47-52, 1994.

[11] OLIVEIRA, M.E.B.; BASTOS, M.S.R.; FEITOSA, T.; BRANCO, M.A.A.C.; SILVA, M.G.G. Avaliação de parâmetros de qualidade físico-químicos de polpas congeladas de acerola, cajá e caju. Ciência e Tecnologia de Alimentos, Campinas, v. 19, n. 3, set./dez., p. 326-332, 1999.

[12] PINTO W.S.; DANTAS, A.C.V.L.; FONSECA, A.A.O.; LEDO, C.A.S.; JESUS, S.C.; CALAFANGE, P.L.P.; ANDRADE, E.M. Caracterização física, físico-química e química de frutos de genótipos de cajazeiras. Pesquisa Agropecuária Brasileira, Brasília, v. 38, n. 9, p. 1059-1066, set. 2003.

[13] PIRES, M.G.M. Estudo Taxonômico e Área de Ocorrência de Umbuzeiro (Spondias tuberosa Arr. Cam.) no Estado de Pernambuco. Brasil. Recife. UFRPE, 1990. 290 p. Dissertação (Mestrado em Botânica). Universidade Federal Rural de Pernambuco.

[14] SANTOS, G.M. Caracterização de Frutos de Cajá (Spondias mombim L.) e Cajá-umbu (Spondias spp.) e Teores de NPK em Folhas e Frutos. Areia: UFPB/CCA, 1996. 68 p. Trabalho de conclusão de curso (Graduação em Agronomia). Universidade Federal da Paraíba.

[15] SILVA JÚNIOR, J. F.; BEZERRA, J.E.F.; LEDERMAN, I.E.; ALVES, M.A.; MELO NETO, M.L. Collecting, ex situ conservation and characterization of "cajá-umbu" (Spondias mombim x Spondias tuberosa) germ-plasm in Pernambuco State, Brazil. Genetic Resources and Crop Evolution, 51: 343-349, 2004.

[16] SOUZA, F.X.; SOUZA, F.H.L.; FREITAS, J.B.S. Caracterização morfológica de endocarpos de umbu-cajá. In: Congresso nacional de botânica, 48, 1997, Crato, CE. Resumos... Fortaleza: SBB/BNB. p. 121. 1997.

[17] SOUZA, V.A.B. Perspectivas do Melhoramento de Espécies Nativas do Nordeste Brasileiro. In: Congresso brasileiro de melhoramento genético de plantas, 1, 2001, Goiânia-GO. Resumo 25, EMBRAPA Meio-Norte, Teresina-PI, 2001.

\section{6 - AGRADECIMENTOS}

Os autores agradecem à Universidade Federal Rural de Pernambuco pela infraestrutura, à CAPES pelo auxílio financeiro e à Empresa Pernambucana de Pesquisa Agropecuária - IPA pelas amostras cedidas. 